OPEN ACCESS

Highly Conductive, Ionic Liquid-Based Polymer Electrolytes

To cite this article: E. Simonetti et al 2017 J. Electrochem. Soc. 164 A6213

View the article online for updates and enhancements. 


\title{
Highly Conductive, Ionic Liquid-Based Polymer Electrolytes
}

\author{
E. Simonetti, ${ }^{a}$ M. Carewska, ${ }^{b}$ G. Maresca, ${ }^{c}$ M. De Francesco, ${ }^{a}$ and G. B. Appetecchi ${ }^{\mathrm{a}, \mathrm{z}}$ \\ ${ }^{a}$ Department SSPT-PROMAS-MATPRO, ENEA, Italian National Agency for New Technologies, \\ Energy and Sustainable, Economic Development, Rome 00123, Italy \\ ${ }^{b}$ Department DTE-PCU-SPCT, ENEA, Rome 00123, Italy \\ ${ }^{c}$ Department of Chemistry, La Sapienza University of Rome, Rome 00185, Italy
}

\begin{abstract}
In this manuscript is reported a thermal and impedance spectroscopy investigation carried out on quaternary polymer electrolytes, to be addressed as separators for lithium solid polymer batteries, containing large amount of the $N$-methyl- $N$-propylpyrrolidinium bis(fluorosulfonyl)imide ionic liquid. The target is the development of $\mathrm{Li}^{+}$conducting membranes with enhanced ion transport even below room temperature. Polyethylene oxide and polymethyl methacrylate were selected as the polymeric hosts. A fully dry, solvent-free procedure was followed for the preparation of the polymer electrolytes, which were seen to be self-consistent and handled even upon prolonged storage periods (more than 1 year). Appealing ionic conductivities were observed especially for the PEO electrolytes, i.e., $1.6 \times 10^{-3}$ and $1.5 \times 10^{-4} \mathrm{~S} \mathrm{~cm}^{-1}$ were reached at 20 and $-20^{\circ} \mathrm{C}$, respectively, which are ones the best, if not the best ion conduction, never detected for polymer electrolytes.

(c) The Author(s) 2016. Published by ECS. This is an open access article distributed under the terms of the Creative Commons Attribution 4.0 License (CC BY, http://creativecommons.org/licenses/by/4.0/), which permits unrestricted reuse of the work in any medium, provided the original work is properly cited. [DOI: 10.1149/2.0331701jes] All rights reserved.

(cc) BY
\end{abstract}

Manuscript submitted September 28, 2016; revised manuscript received November 7, 2016. Published December 7, 2016. This was Paper 701 presented at the Chicago, Illinois, Meeting of the IMLB, June 19-24, 2016. This paper is part of the Focus Issue of Selected Papers from IMLB 2016 with Invited Papers Celebrating 25 Years of Lithium Ion Batteries.

Lithium polymer batteries (LPBs) are considered excellent candidates for the next generation power sources because they combine high energy density and flexible characteristics with the safety issue of the solvent-free electrolytes. ${ }^{1}$ Nevertheless, the performance of LPBs is limited by the low ionic conductivity of the solvent-free polymer electrolytes at room temperature as the polymeric host is manly crystalline (i.e., resulting in slow motion of the $\mathrm{Li}^{+}$active specie). ${ }^{2}$ For instance, polyethylene oxide- (PEO) based electrolytes exhibit suitable conduction values $\left(\geq 10^{-4} \mathrm{~S} \mathrm{~cm}^{-1}\right)$ for practical applications only above $65^{\circ} \mathrm{C}$, e.g., where the amorphous phase is predominant and allows remarkably higher mobility to the lithium ions. ${ }^{3-5}$ Therefore, several approaches ${ }^{6}$ were attempted aiming to decrease the content of crystalline phase (particularly, $\left.\mathrm{P}(\mathrm{EO})_{6} \mathrm{LiX}\right)^{3-5}$ in polymer electrolytes, e.g., branched and/or cross-linked hosts, blended polymer matrices, large counter anion lithium salts, addition of additives (organic compounds, oligomers, ceramic fillers).

One of the most promising approaches is represented by the incorporation of ionic liquids (ILs) into the polymer electrolytes. ${ }^{6}$ In the last years it was successfully demonstrated ${ }^{6}$ that incorporation of $N$-alkyl- $N$-methylpyrrolidinium $\left(\mathrm{PYR}_{1 \mathrm{~A}}\right.$, where the subscripts indicate the number of carbon atoms of the pyrrolidinium cation alkyl chains) perfluorosulfonylimide (PFSI) ILs enhances the room temperature ionic conductivity of solid polymer electrolytes (SPEs) above $10^{-4} \mathrm{Scm}^{-1}$ and improves the compatibility with respect to the lithium anode.

However, faster ion transport properties are needed, especially in devices (operating at high current rates) for applications (i.e., automotive) requiring higher power density values. In the frame of the MARS-EV project ${ }^{7}$ we have properly designed and developed SPEs based on PEO and polymethyl methacrylate (PMMA), i.e., considered ones of the most suitable materials as host for polymer electrolytes, ${ }^{6}$ and incorporating large fraction of $N$-methyl- $N$-propylpyrrolidinium bis(fluorosulfonyl)imide, $\mathrm{PYR}_{13}$ FSI. This ionic liquid was selected as it combines high ion conduction and low melting point with ability to form stable SEI (Solid Electrochemical Interface) onto lithium and graphite anodes. ${ }^{8}$ Lithium bis(trifluoromethanesulfonyl)imide (LiTFSI) was chosen as the salt because of its high solubility (even in suitable polymer hosts), ${ }^{6}$ good ion transport properties and wide electrochemical stability. ${ }^{9}$ Also, the addition of proper additives (ethylene carbonate, EC) in small amount, aiming to improve the interface with

${ }^{\text {z} E-m a i l: ~ g i a n n i . a p p e t e c c h i @ e n e a . i t ~}$ graphite anodes, was considered (small alkyl carbonates contents were seen to not deplete the electrolyte safety, ${ }^{10}$ i.e., the organic additive is mainly consumed during the first cycle in battery).

The PEO and PMMA quaternary electrolyte samples were investigated, as a function of the IL content and temperature, in terms of thermal and ion transport properties.

\section{Experimental}

The $\mathrm{PYR}_{13}$ FSI ionic liquid was synthesized through an ecofriendly procedure properly designed and developed at ENEA and reported elsewhere. ${ }^{11}$ The residual content of lithium, halide and moisture was found to be lower than $2 \mathrm{ppm}$.

The PEO-LiTFSI-PYR ${ }_{13}$ FSI-EC and PMMA-LiTFSI-PYR ${ }_{13}$ FSIEC quaternary polymer electrolytes were prepared through a solventfree hot-pressing process, ${ }^{6}$ performed in a very low relative humidity $\left(<0.1 \%\right.$ at $\left.20^{\circ} \mathrm{C}\right)$ dry room and schematically illustrated in Figure $1 \mathrm{~A}$. LiTFSI (3 M, battery grade, > 99.9\%), PYR ${ }_{13}$ FSI, PEO (Dow Chemicals, WSR 301, $\mathrm{M}_{\mathrm{W}}=4,000,000$ ) and PMMA (Aldrich, $\mathrm{M}_{\mathrm{W}}=$ $996,000)$ were vacuum dried at $120^{\circ} \mathrm{C}$ (24 hours), $70^{\circ} \mathrm{C}$ ( 2 days), $50^{\circ} \mathrm{C}$ ( 2 days) and $70^{\circ} \mathrm{C}$ ( 2 days), respectively. EC (Merck, battery grade, $>99.9 \%$, moisture content $<20 \mathrm{ppm}$ ) was used as received. As the EO and MMA monomers have different molecular weight, the EO:Li and MMA:Li mole ratios were fixed equal to $=20: 1$ and 8.8:1, respectively, in order to keep the same monomer: salt (and monomer : ionic liquid) weight ratio. PEO or PMMA and LiTFSI were mixed in a mortar and, then, $\mathrm{PYR}_{13} \mathrm{FSI}$ and $\mathrm{EC}$ were added in the proper proportions. The $\left(\mathrm{PYR}_{13}\right)^{+}: \mathrm{Li}^{+}$mole ratio was ranged from 0 to 7 whereas the EC content was fixed to $8 \mathrm{wt} \%$ (7.4 wt\% of the overall sample weight) with respect to the PEO(PMMA)-LiTFSI-PYR ${ }_{13}$ FSI mass. Upon further mixing, the electrolytic blend was housed in vacuumsealed pouch envelope and annealed at $70^{\circ} \mathrm{C}$ overnight in order to homogenize the components. A plastic-like bulk past, having a thickness from 4 to $5 \mathrm{~mm}$ and opaque appearance, was obtained, which was hot-pressed at $80^{\circ} \mathrm{C}$ for 2 minutes to form 50 to $100 \mu \mathrm{m}$ thick trans-lucid films. However, in order to minimize the error on the electrolyte thickness, the conductivity measurements were performed on 500-600 $\mu \mathrm{m}$ thick membranes.

Differential scanning calorimetry (DSC) measurements were performed using a thermal analyzer system DSC TA Instruments. The polymer electrolytes (about $5 \mathrm{mg}$ ) were sealed in aluminum DSC pan inside the dry room. The samples were initially cooled at $10^{\circ} \mathrm{C} \mathrm{min}{ }^{-1}$ 

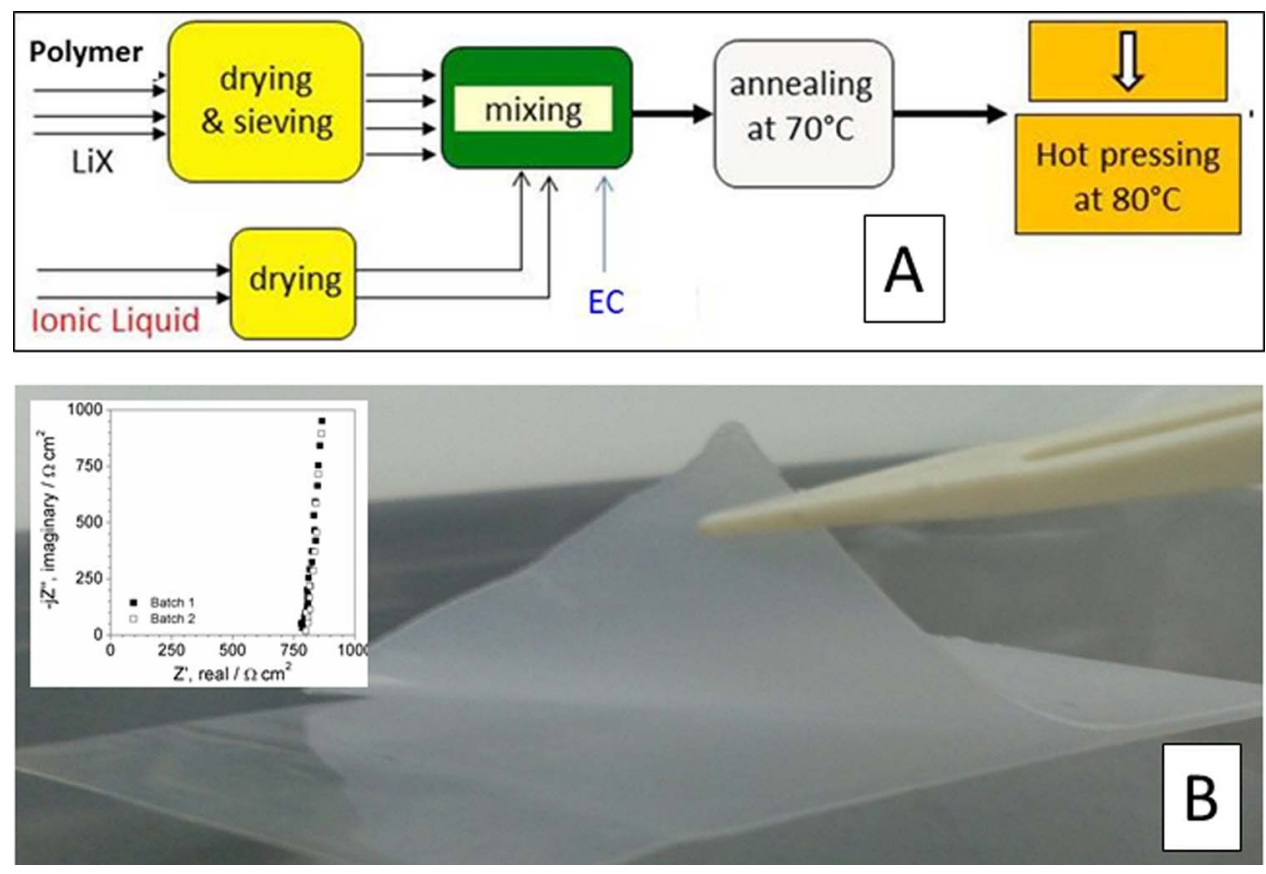

Figure 1. Panel A: schematic representation of the solvent-free procedure designed for the preparation of the dry polymer electrolytes. Panel B: picture of a PEO-8 quaternary polymer electrolyte sample as prepared. The insert in panel B reports the impedance response, normalized with respect to the cell constant, of two fresh PEO-8 samples coming from different batches. $\mathrm{T}=20^{\circ} \mathrm{C}$.

from room temperature down to $-140^{\circ} \mathrm{C}$ and, then, heated at $10^{\circ} \mathrm{C}$ $\min ^{-1}$ to $150^{\circ} \mathrm{C}$ with $50 \mathrm{~mL} \mathrm{~min}{ }^{-1}$ helium flow rate.

The ionic conductivity was determined by impedance spectroscopy measurements taken on symmetrical, two-electrode cells kept in OCV condition. The $\mathrm{AC}$ tests were run in the $-40 / 100^{\circ} \mathrm{C}$ temperature interval by means of a F. R. A. Schlumberger Solartron 1260. During the experiments, performed applying a $\Delta \mathrm{V}=10 \mathrm{mV}$ sinusoidal amplitude in the $65,000-1 \mathrm{~Hz}$ frequency range, the cells were located in a climatic test chamber (Binder GmbH MK53) with a temperature control of $\pm 0.1^{\circ} \mathrm{C}$. Prior the measurements, the cells were held at $-40^{\circ} \mathrm{C}$ for at least 24 hours and, then, subjected to a heating scan (up to $100^{\circ} \mathrm{C}$ ) at $10^{\circ} \mathrm{C} \mathrm{day}^{-1}$ (scan) rate.

The conductivity cells were manufactured within the dry room by sandwiching a polymer electrolyte tape between two copper tapes
(30 $\mu \mathrm{m}$ thick, active area $=1 \mathrm{~cm}^{2}$ ). The so-assembled cells were housed in sealed pouch envelopes and, successively, laminated twice by hot-rolling at $100^{\circ} \mathrm{C}$ to improve the electrolyte/electrode interfacial contact.

\section{Results and Discussion}

In Table I is summarized the weight composition of the PEOand PMMA-based quaternary electrolyte samples investigated in the present work. Free-standing, handled membranes (Figure 1B) were obtained up to an ionic liquid content of 60 and $53 \%$ in weight, and even upon prolonged storage times, for the PEO and PMMA electrolyte systems, respectively. For higher IL fractions the electrolyte membranes become paste-like and, therefore, were not investigated.

Table I. Weight composition and ionic conductivity (referred to the equilibrium state) of the investigated polymer electrolyte samples. The monomer:lithium salt and ionic liquid:lithium salt mole ratios are also reported.

\begin{tabular}{|c|c|c|c|c|c|c|c|c|}
\hline \multirow[b]{2}{*}{ Sample } & \multirow[b]{2}{*}{ EO:Li mole ratio } & \multirow[b]{2}{*}{$\mathrm{PYR}_{13}: \mathrm{Li}$ mole ratio } & \multirow[b]{2}{*}{$\mathrm{PEO} / \mathrm{wt} \%$} & \multirow[b]{2}{*}{ LiTFSI/wt\% } & \multirow[b]{2}{*}{$\mathrm{PYR}_{13} \mathrm{FSI} / \mathrm{wt} \%$} & \multirow[b]{2}{*}{$\mathrm{EC} / \mathrm{wt} \%$} & \multicolumn{2}{|c|}{$\sigma / \mathrm{S} \mathrm{cm}^{-1}$} \\
\hline & & & & & & & $-20^{\circ} \mathrm{C}$ & $20^{\circ} \mathrm{C}$ \\
\hline PEO-1 & 20 & 0 & 75.4 & 24.6 & 0 & 0 & n. a. & $2.3 \times 10^{-6}$ \\
\hline PEO-2 & 20 & 0 & 69.8 & 22.8 & 0 & 7.4 & n. a. & $2.8 \times 10^{-5}$ \\
\hline PEO-3 & 20 & 0.5 & 61.7 & 20.1 & 10.8 & 7.4 & n. a. & $1.6 \times 10^{-4}$ \\
\hline PEO-4 & 20 & 1.0 & 55.3 & 18.0 & 19.3 & 7.4 & $2.9 \times 10^{-6}$ & $1.8 \times 10^{-4}$ \\
\hline PEO-5 & 20 & 2.0 & 45.7 & 14.9 & 32.0 & 7.4 & $9.7 \times 10^{-5}$ & $9.7 \times 10^{-4}$ \\
\hline PEO-6 & 20 & 3.0 & 39.0 & 12.7 & 40.9 & 7.4 & $9.7 \times 10^{-5}$ & $8.3 \times 10^{-4}$ \\
\hline PEO-7 & 20 & 4.0 & 42.1 & 13.7 & 44.2 & 0 & $1.1 \times 10^{-4}$ & $8.6 \times 10^{-4}$ \\
\hline PEO-8 & 20 & 4.0 & 34.0 & 11.1 & 47.5 & 7.4 & $1.3 \times 10^{-4}$ & $1.6 \times 10^{-3}$ \\
\hline PEO-9 & 20 & 5.0 & 30.1 & 9.8 & 52.7 & 7.4 & $1.5 \times 10^{-4}$ & $1.1 \times 10^{-3}$ \\
\hline PEO-10 & 20 & 6.0 & 27.0 & 8.8 & 56.8 & 7.4 & $1.5 \times 10^{-4}$ & $1.1 \times 10^{-3}$ \\
\hline PEO-11 & 20 & 7.0 & 24.5 & 8.0 & 60.1 & 7.4 & $\begin{array}{r}1.5 \times 10^{-4} \\
\sigma / S\end{array}$ & $\mathrm{~m}^{-1} .6 \times 10^{-4}$ \\
\hline Sample & MMA:Li mole ratio & $\mathrm{PYR}_{13}: \mathrm{Li}$ mole ratio & PMMA / wt $\%$ & LiTFSI / wt $\%$ & $\mathrm{PYR}_{13} \mathrm{FSI} / \mathrm{wt} \%$ & $\mathrm{EC} / \mathrm{wt} \%$ & $-20^{\circ} \mathrm{C}$ & $-20^{\circ} \mathrm{C}$ \\
\hline PMMA-1 & 8.8 & 3.0 & 39.0 & 12.7 & 40.9 & 7.4 & n. a. & $2.4 \times 10^{-8}$ \\
\hline PMMA-2 & 8.8 & 4.0 & 34.0 & 11.1 & 47.5 & 7.4 & $1.2 \times 10^{-7}$ & $4.2 \times 10^{-5}$ \\
\hline PMMA-3 & 8.8 & 5.0 & 30.1 & 9.8 & 52.7 & 7.4 & $1.2 \times 10^{-6}$ & $5.4 \times 10^{-5}$ \\
\hline
\end{tabular}




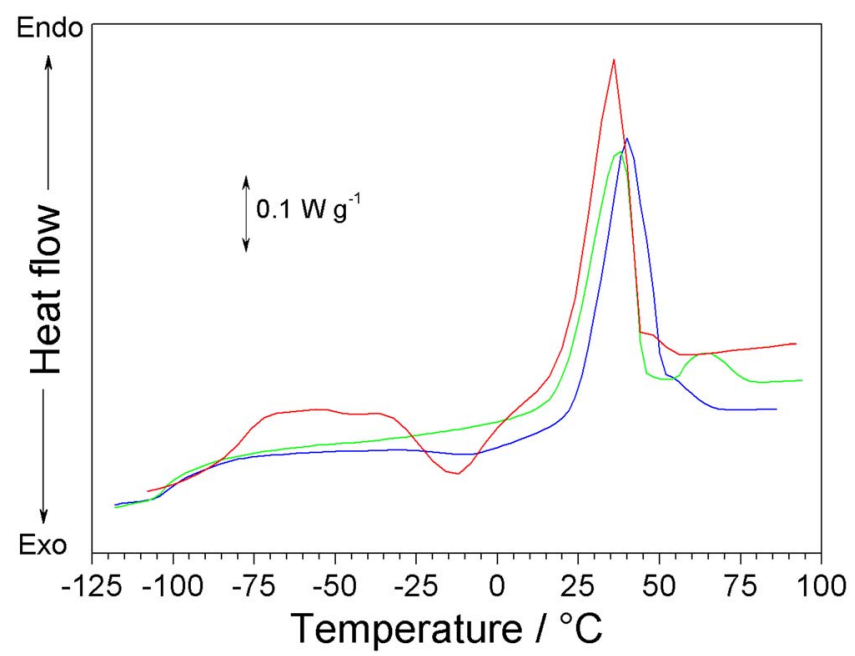

Figure 2. Heating DSC traces, obtained according to different test protocols, of the PEO-8 polymer electrolyte sample. Scan rate: $10^{\circ} \mathrm{C} \mathrm{min}-1$.

The reproducibility of the preparation route was checked by impedance measurements carried out at $20^{\circ} \mathrm{C}$ on polymer electrolyte samples having identical formulation, but coming from different batches. As example, the insert in Figure 1B compares the impedance response $\left(20^{\circ} \mathrm{C}\right)$, normalized with respect to the cell constant, of two PEO-8 samples. The AC plots are practically overlapped, indicating that the properly developed preparation procedure is highly reproducible. Also, the homogeneity of the fresh electrolyte membranes was checked by impedance measurements performed (at $20^{\circ} \mathrm{C}$ ) in different regions of the samples. Reproducible conductivity results were recorded both for thin $(50-100 \mu \mathrm{m})$ and thick $(500-600 \mu \mathrm{m})$ membranes.
The thermal properties of PEO- and PMMA-based quaternary polymer electrolytes were investigated by DSC analysis. It should be noted how the test protocol may affect the thermal behavior as reported in Figure 2 for the PEO- 8 sample. The three DSC traces are referred to heating scans obtained after subjecting the test samples to different procedures. The red profile was recorded after $(i)$ initial heating (from room temperature) up to $90^{\circ} \mathrm{C}$ followed by (ii) cooling down to $-120^{\circ} \mathrm{C}$. A broad exothermic feature (already detected during the cooling scan), due to cold crystallization of the still partially amorphous electrolytic sample, is observed around $-12^{\circ} \mathrm{C}$ whereas a well pronounced endothermic melting peak is centered at $37^{\circ} \mathrm{C}$. The green heating scan was run upon $(i)$ cooling down to $120^{\circ} \mathrm{C}$, followed by (ii) heating up to $0^{\circ} \mathrm{C}$ (end of exothermal feature in the red trace) and (iii) further cooling (down to $120^{\circ} \mathrm{C}$ ). No exothermal feature is observed whereas a glass transition $\left(\mathrm{T}_{\mathrm{g}}\right)$ profile is noticed around $-103^{\circ} \mathrm{C}$. In addition, the melting peak is seen to be split (already observed in the red trace) in a main feature, e.g., located around $37^{\circ} \mathrm{C}$, and a much weaker profile centered at $65^{\circ} \mathrm{C}$. This behavior may be attributed to heterogeneous phases within the polymer electrolyte. Finally, prior carrying out the blue heating scan, the sample was (i) cooled down to $-120^{\circ} \mathrm{C}$, (ii) heated up to $90^{\circ} \mathrm{C}$, (iii) cooled down $-120^{\circ} \mathrm{C}$ and $(\mathrm{iv})$ kept at this temperature for 15 minutes. This procedure led to reduced splitting of the melting peak, e.g., the main feature is slightly shifted to higher temperature (about $40^{\circ} \mathrm{C}$ ) whereas another, but much weaker, profile is located around $50^{\circ} \mathrm{C}$. To summarize, besides to differences in the thermal profile, the results obtained by different DSC test protocols indicate, however, not homogenous composition within the quaternary polymer electrolytes. This seems to be also supported by the appearance of liquid leakage (mainly ionic liquid) onto the electrolytic membrane surface after few days of storage.

Figure 3 illustrates the heating DSC traces of PEO-based (panel A) and PMMA-based (panel C) polymer electrolytes. The glass transition temperature region is magnified in panels $\mathrm{B}$ (PEO-based samples) and D (PMMA-based samples), respectively. The pure polymer hosts are reported for comparison purpose. (The thermal scans were run after subjecting the samples to the same protocol adopted for obtain-
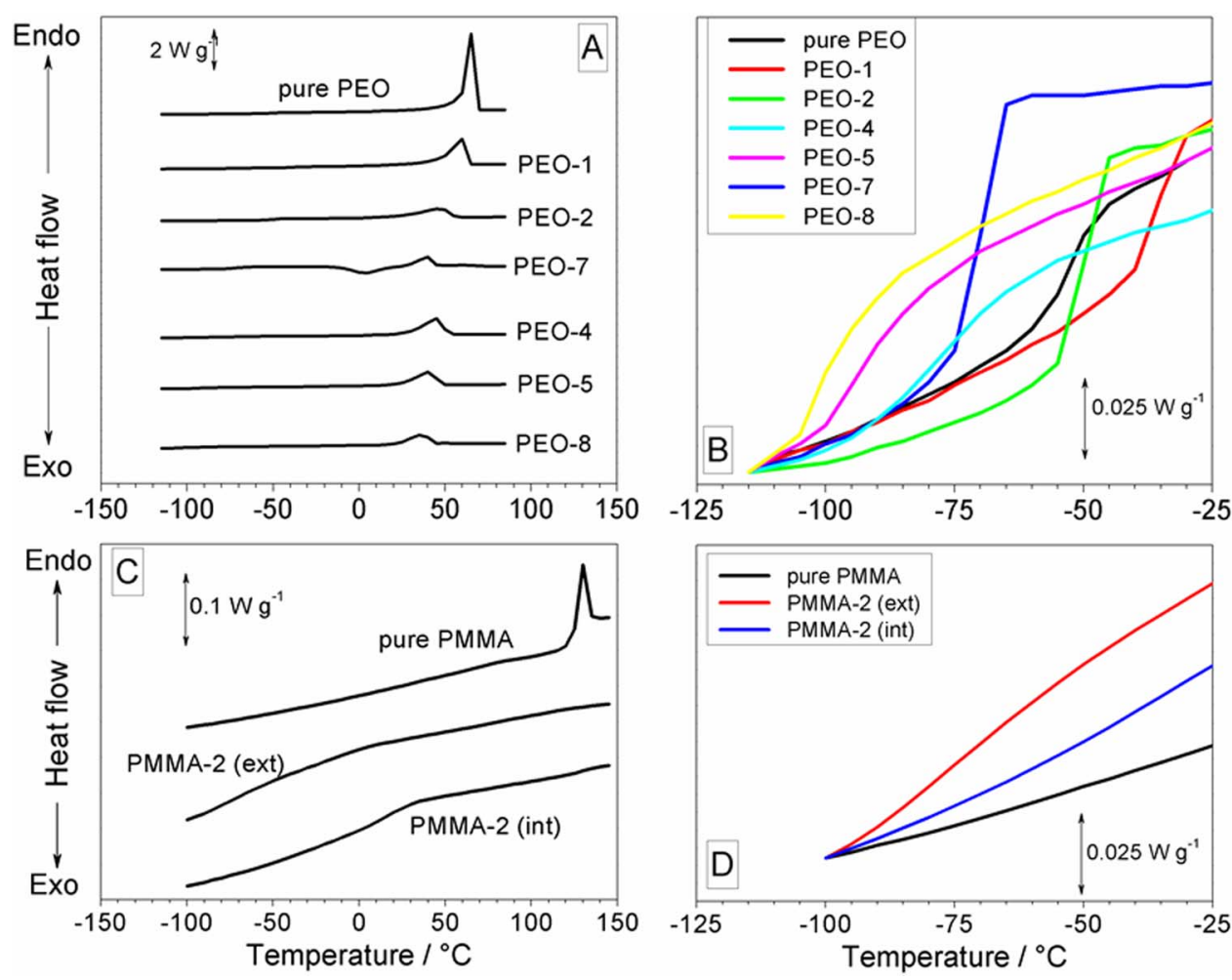

Figure 3. Heating DSC trace of PEO-based (panel A) and PMMA-based (panel C) polymer electrolytes. The glass transition temperature region is magnified in panels B (PEO-based samples) and D (PMMA-based samples), respectively. The pure polymer hosts are reported for comparison purpose. Scan rate: $10^{\circ} \mathrm{C}$ min ${ }^{-1}$ 
ing the blue trace in Figure 2.) It is to note the plasticizing effect due to large counter ion lithium salts as LiTFSI salt, ${ }^{12}$ leading to broader (endothermic) melting peak shifted from 65 to $59^{\circ} \mathrm{C}$ (PEO-1) with respect to pure $\mathrm{PEO} .^{3-5}$ In addition, a glass transition feature is observed around $-35^{\circ} \mathrm{C}$ (red trace in panel $\mathrm{B}$ ). The addition of even small EC amounts (PEO-2) results in shifting of the (weaker) melting peak $\left(47^{\circ} \mathrm{C}\right)$ as well as the $\mathrm{T}_{\mathrm{g}}$ profile $\left(50^{\circ} \mathrm{C}\right.$, green trace in panel B) toward lower temperatures. This suggests progressive increase of amorphous phase content, moving from pure PEO host to binary and ternary polymer electrolytes, ascribable to lithium salts and additives. ${ }^{13,14}$ Increasing incorporation of ionic liquid leads to more and more amorphous electrolyte membranes, ${ }^{6}$ indicated by progressive shift of the melting peak (panel $\mathrm{A}$ ) and $\mathrm{T}_{\mathrm{g}}$ profile (panel B) from 47 and $50^{\circ} \mathrm{C}$, respectively (e.g., detected in the (IL-free) PEO-2 ternary sample), up to 34 and $-100^{\circ} \mathrm{C}$ (e.g., observed in the PEO-8 quaternary systems at $\mathrm{PYR}_{13}: \mathrm{Li}$ mole ratio $=4: 1$ ). This is a clear highlight of the plasticizing role played by ionic liquids in solid polymer electrolytes. The PEO-LiTFSI-PYR ${ }_{13}$ FSI (PEO-7) ternary sample shows appreciable exothermal feature (due to cold crystallization), i.e., not observed in the EC-containing quaternary electrolytes, as well as a better evidenced glass transition profile (blue trace in panel B) around $-70^{\circ} \mathrm{C}$. Possible explanation could be incomplete crystallization of PEO-7 due to absence of EC (e.g., able to interact both with the PEO host $^{13,14}$ and ionic liquid ${ }^{10}$ ), which leads to slower (crystallization) kinetics.

Figure 3B compares the DSC trace of the PMMA-2, P(MMA $)_{8.8}(\mathrm{LiTFSI})_{1}\left(\mathrm{PYR}_{13} \mathrm{FSI}\right)_{4}$, with that of pure crystalline PMMA. The pristine polymer host shows a well-defined melting endothermic feature around $125^{\circ} \mathrm{C},{ }^{15}$ which is seen to be reduced in much broader and weaker peak and to be shifted toward much lower temperature in the PMMA-2 electrolyte, once more indicating that the polymer host is almost fully amorphous. The glass transition profile is not easily detectable (panel D). In addition, the thermal trace of PMMA-2 is seen to differ depending on the analyzed sample region. For instance, a shift of the melting peak, also turning in broader and weaker feature, from 30 to $10^{\circ} \mathrm{C}$ is seen in moving from the core (PMMA-2 int. trace) to the external region (PMMA-2 ext. trace) of the sample. These results, suggesting not homogeneous composition within the electrolyte membrane, indicate better plasticizing effect on the polymer matrix in the external region, likely due to higher ionic liquid content.

The impedance of the conductivity cells (stored in open circuit voltage, OCV, condition) was monitored as a function of the storage time at $20^{\circ} \mathrm{C}$ in order to investigate the ageing resistance of the polymer electrolytes. As example, Figure 4 plots the $\mathrm{AC}$ responses of $\mathrm{Cu} / \mathrm{PEO}-8$ / $\mathrm{Cu}$ (panel A) and $\mathrm{Cu} / \mathrm{PMMA}-3 / \mathrm{Cu}$ (panel B) cells taken at different time periods. The bulk ionic conductivity of the PEO polymer electrolyte sample under test is given by the high frequency intercept of the AC plot with the real axis (distance from the axes origin). ${ }^{16}$ No change of the Nyquist feature, constituted by just an inclined straight line with respect to the real axis, is observed even upon about one year and half of storage. From Figure 4A it is evidenced a progressive reduction of the electrolyte resistance during the initial period of storage whereas no further decrease is noticed after three days, e.g., identical bulk resistance values are found even upon very prolonged storage times (17 months). All PEO-based electrolytes (with the exception of the ionic liquid-free sample, likely due to slow crystallization kinetics of the PEO host in presence of large lithium salt counter ions) ${ }^{12}$ exhibited analogous behavior, e.g., an initial impedance decrease followed by time-stable resistance values. This means progressive increase in conductivity (depending of the inverse of the electrolyte resistance) during the initial storage period to leveling around time-stable values. Conversely, the PMMA-based sample (panel B) shows opposite behavior, i.e., initial increase of the bulk resistance prior achieving an equilibrium state. In addition, the AC plots taken after about 4 months of storage exhibit a semicircle (i.e., not evidenced until 64 days) which, however, does not change even after very prolonged storage (more than 16 months). The presence of the arc (i.e., not starting from the origin) in the medium-high
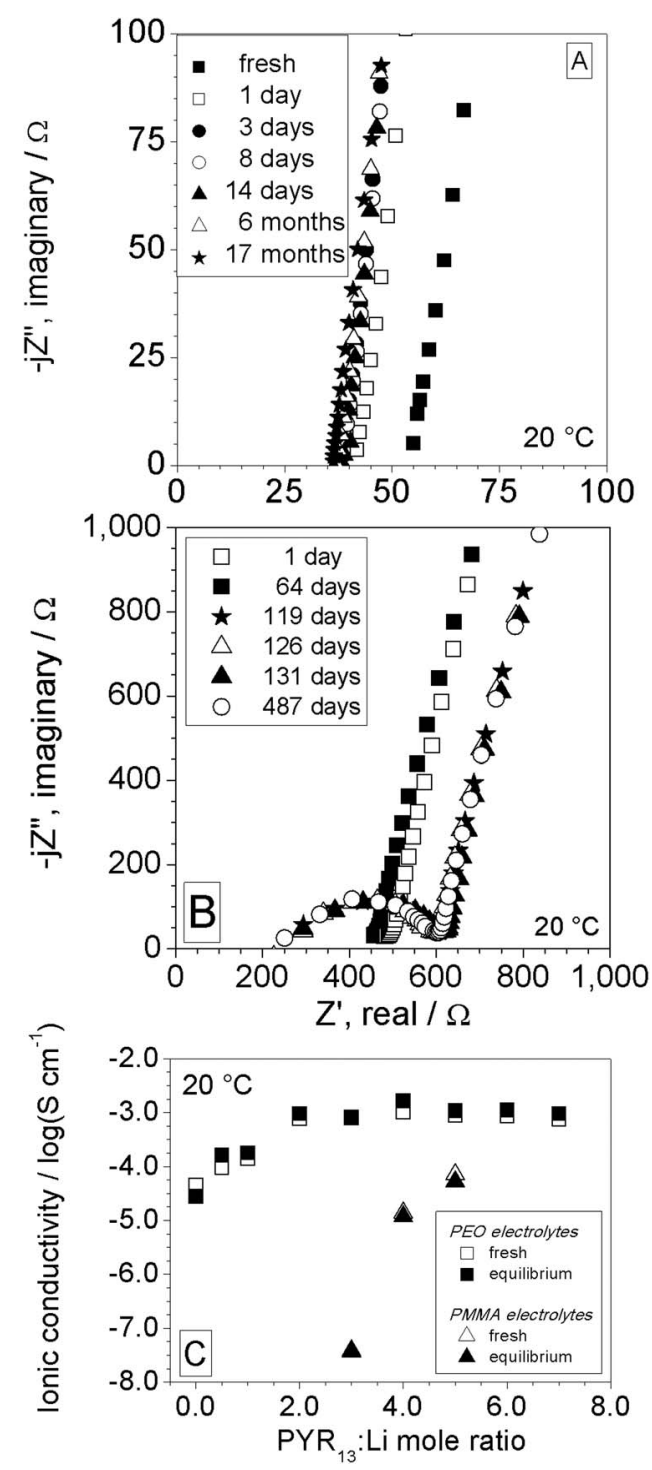

Figure 4. Nyquist plots taken on $\mathrm{Cu} / \mathrm{PEO}-8 / \mathrm{Cu}$ (panel A) and $\mathrm{Cu} / \mathrm{PMMA}$ $3 / \mathrm{Cu}$ (panel B) cells after different storage times at $20^{\circ} \mathrm{C}$. Panel $\mathrm{C}$ : ionic conductivity vs $\mathrm{PYR}_{13}: \mathrm{Li}$ mole ratio dependence of PEO-based (squares) and PMMA-based (triangles) quaternary polymer electrolytes. The data are referred to the samples both as prepared (open data markers) and at equilibrium state (full data markers). $\mathrm{T}=20^{\circ} \mathrm{C}$.

frequency region indicates that the overall sample resistance is constituted by two contributes, namely the bulk one (given by the intercept of the high frequency semicircle with the real axis) and a grain boundary resistance (given by the semicircle diameter), ${ }^{16}$ likely ascribable to heterogeneous phases within the electrolyte sample. It is to note how the PMMA-based electrolyte achieves an equilibrium state after more than two months instead 3 days as observed for the PEO sample, suggesting much slower structural rearrangements and/or phase separations.

Figure 4C reports the ionic conductivity vs ionic liquid:lithium salt $\left(\mathrm{PYR}_{13}: \mathrm{Li}\right)$ mole ratio dependence for the PEO- (square data markers) and PMMA-based (triangles) polymer electrolytes. The data (obtained at $20^{\circ} \mathrm{C}$ ) are referred both to the fresh samples (open data markers) and after achievement of the equilibrium state (full data markers). A moderate increase in conductivity, with respect to that of the fresh sample, is recorded for the PEO electrolytes (independently on the ionic liquid content) whereas opposite trend is displayed by the PMMA samples. The PEO electrolytes exhibit a progressive rise in conductivity (Table I) of about two orders of magnitude (from 

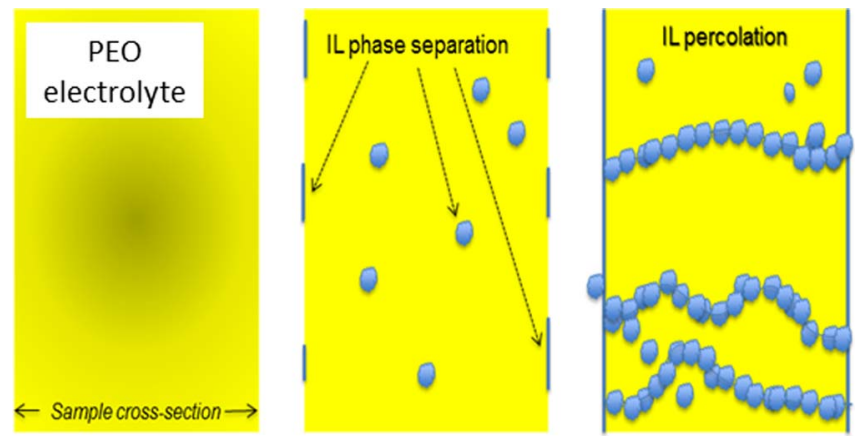

fresh

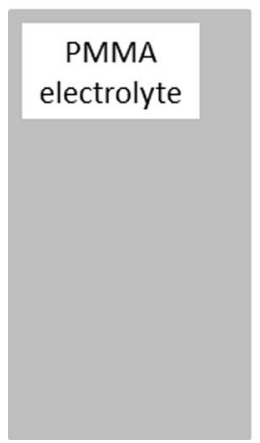

a few days later

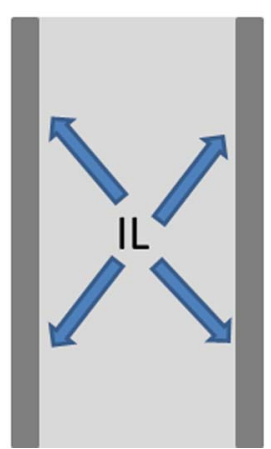

Figure 5. Schematic representation of phase separation phenomena taking place during storage time in ionic liquid rich, PEO-based (upper panels) and PMMA-based (lower panels) quaternary electrolytes.

about $3 \times 10^{-5}$ to $10^{-3} \mathrm{~S} \mathrm{~cm}^{-1}$ ) up to a $\mathrm{PYR}_{13}: \mathrm{Li}$ mole ratio $=2$. No conduction increase is seen within the $\mathrm{PYR}_{13}: \mathrm{Li}$ mole ratio range from 2 to 7 , in which the conductivity value levels around $10^{-3} \mathrm{~S}$ $\mathrm{cm}^{-1}$. The PMMA electrolytes exhibit a ion conduction gain above three orders of magnitude (from about $3 \times 10^{-8}$ to $10^{-4} \mathrm{~S} \mathrm{~cm}^{-1}$ ) in passing from $\mathrm{PYR}_{13}: \mathrm{Li}=3$ to 5 (Table I). For instance, the presence of the ionic liquid component is able both of plasticizing the polymeric host chains, enhancing the conductive amorphous phase content, and to reduce the polymer - lithium cation interaction, largely improving the mobility of the $\mathrm{Li}^{+}$ion. ${ }^{6}$

The results obtained from thermal and impedance measurements seem to support for ionic liquid percolation ${ }^{17}$ through the bulk of the PEO quaternary systems. For instance, the change in ion conduction of Figure $4 \mathrm{C}$ shows two different trends as the $\mathrm{PYR}_{13}$ : $\mathrm{Li}$ mole ratio is increased:

1 An initial region, e.g., from $0 \leq \mathrm{PYR}_{13}: \mathrm{Li} \leq 2$, where ionic liquid clusters (coming from phase separation) are initially separated from each other, but IL pathways are progressively formed through the electrolyte membrane as the $\mathrm{PYR}_{13} \mathrm{FSI}$ content is increased. In this region the slope of the conductivity vs $\mathrm{PYR}_{13}$ :Li mole ratio dependence is relatively high because of the remarkable increase in ion conduction given by conductive, ionic liquid pathways.

2 A second region, e.g., from $2<\mathrm{PYR}_{13}: \mathrm{Li} \leq 7$, in which the percolation limit is achieved and the ionic conductivity does not substantially change as the ionic liquid content is increased.

A schematic model of the chemical behavior of the quaternary PEO systems is reported in Figure 5 (upper panels). Phase separation of ionic liquid (or IL-LiTFSI-EC), evidenced by liquid leakage appearance (especially at high IL contents) onto the sample surface after few days of storage (e.g., no liquid release is observed on fresh samples), occurs in the polymer membranes, likely ascribable to IL excess that cannot be coordinated by $\mathrm{Li}^{+}$cations. ${ }^{6}$ This leads to liquid segregation also within the electrolyte bulk. Therefore, it is possible to hypothesize ionic liquid percolation through the polymer electrolytes during

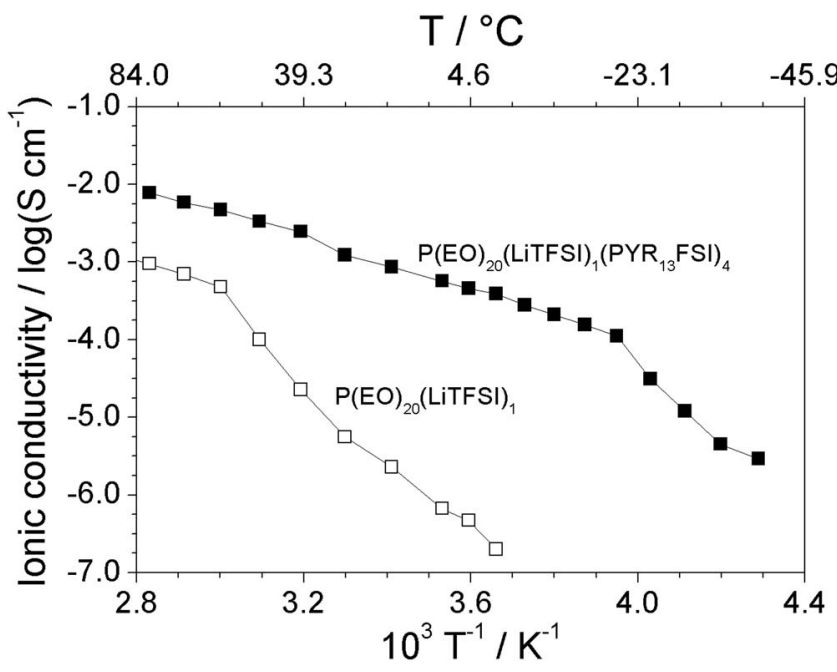

Figure 6. Arrhenius conductivity plot of the PEO-1 (open squares) and PEO-7 (full squares) electrolyte samples.

the beginning of the storage, resulting in three-dimensional network of highly conductive (IL) pathways responsible of the raise in ion conduction. After few days of storage, no variation of the impedance response (and, therefore, of the conduction value) is observed in PEO electrolytes, indicating that an ageing resistant equilibrium state between segregated liquid phase and polymer electrolyte bulk is achieved (Figures 4A and 4C). We would like to highlight that phase separation (i.e., liquid leakage) is generally an unwelcome behavior in polymer electrolytes. However, the purpose to incorporate large IL amounts was to promote creation of 3-D conductive structures to enhance the ion transport properties. In addition, the liquid film released onto the electrolyte membrane surface is expected to improve the interfacial compatibility with electrodes.

The data obtained for the PMMA quaternary system do not suggest formation of conductive pathways through the electrolyte bulk as the ion conduction is seen to initially decrease with the storage time. As the PMMA host (conversely to the PEO one $)^{6}$ is able to interact with ionic liquids, it is reasonable to hypothesize lower liquid release from the sample bulk with respect to the PEO electrolytes. However, the impedance and DSC results support for the formation of heterogeneous phases during the storage. Therefore, a different model is approached as illustrated in the lower panels of Figure 5. We have hypothesized progressive, even if slow, diffusion (during the storage time) of ionic liquid excess, e.g., not coordinated by the PMMA host, from the sample core to the external shell, leading to IL enrichment in external regions (highlighted in dark gray in the lower panels of Figure 5) and, consequently, impoverishment in the internal one (soft gray). The heterogeneity of the PMMA electrolytes, in agreement with the DSC results, would result from different IL distribution through the samples. After more than two months of storage, an equilibrium state is reached, which was found to be chemically stable even after very prolonged time periods.

Figure 6 compares the conductivity vs temperature dependence, reported as Arrhenius plot, of the P(EO) $)_{20}(\mathrm{LiTFSI})_{1}(\mathrm{PEO}-1)$ and $\mathrm{P}(\mathrm{EO})_{20}(\mathrm{LiTFSI})_{1}\left(\mathrm{PYR}_{13} \mathrm{FSI}\right)_{4}$ (PEO-7) samples. The IL-free sample exhibits two linear trends with a slope (e.g., related to the activation energy of the ion conduction mechanism) change (typical of PEOLiX electrolytes) at around $60^{\circ} \mathrm{C}$, coinciding to the melting of the salt rich phase ${ }^{2}$ and in agreement with the DSC results (Figure $3 \mathrm{~A}$ ). The PEO-7 sample exhibits a knee around $-20^{\circ} \mathrm{C}$, likely corresponding to the melting of free, i.e., not bounded to the LiTFSI salt, PYR $_{13}$ FSI ionic liquid ${ }^{18}$ and a moderate conductivity step increase around $40^{\circ} \mathrm{C}$, in agreement with the relatively weak (endothermic) feature observed in the DSC trace (Figure 3A). The incorporation of $\mathrm{PYR}_{13} \mathrm{FSI}$ into the PEO electrolyte bulk results in ion conduction jump up to three orders of magnitude at $20^{\circ} \mathrm{C}$, i.e., from $10^{-6}$ to $10^{-3} \mathrm{~S} \mathrm{~cm}^{-1}$ (Table I), 


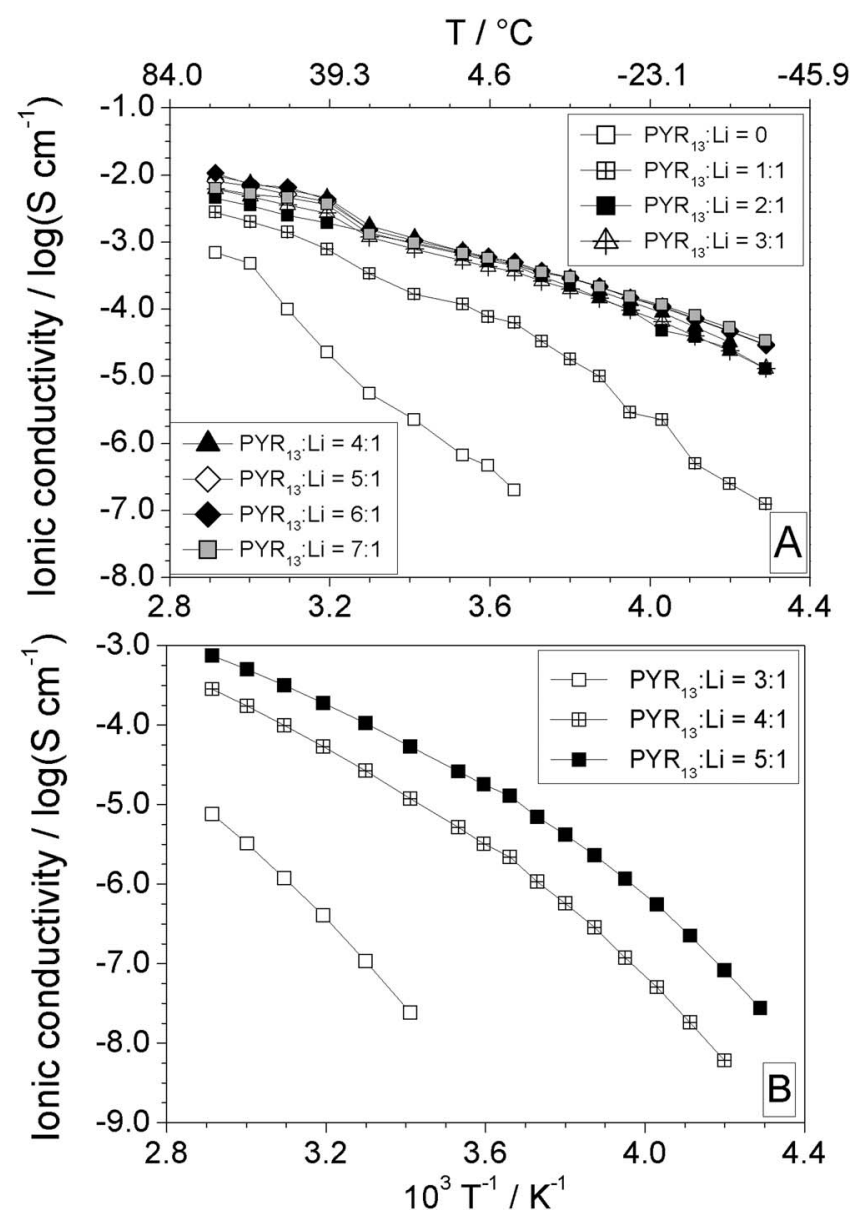

Figure 7. Arrhenius conductivity plot of the PEO-based (panel A) and PMMA-based (panel B) quaternary electrolytes as a function of the $\mathrm{PYR}_{13}: \mathrm{Li}$ mole ratio.

and good conductivity values are achieved even at low temperatures, i.e., above $10^{-4} \mathrm{~S} \mathrm{~cm}^{-1}$ at $-20^{\circ} \mathrm{C}$ (Table I), remarkably highlighting the beneficial effect due to IL. At our sight, these are ones of the best, if not the best, ion conduction values reported in literature till now for ionic liquid-based PEO electrolytes. ${ }^{6}$ It is worth to note that a conductivity increase of one order of magnitude, with respect to the IL-free PEO sample, is seen even at medium-high temperatures (where values around $10^{-2} \mathrm{~S} \mathrm{~cm}^{-1}$ are matched) conversely to results previously reported in literature. ${ }^{6}$ Once more, this likely supports for the establishment of conductive liquid pathways (not observed in other PEO electrolyte membranes), which further improves the ion transport properties.

The ionic conductivity vs temperature dependence of PEO- (panel A) and PMMA-based (panel B) polymer electrolyte systems at different $\mathrm{PYR}_{13}: \mathrm{Li}$ mole ratios is depicted as Arrhenius plot in Figure 7. As also observed in Figure 6, the beneficial effect due to ionic liquid incorporation is clearly evidenced. The conductivity increase is due to the interactions between PYR $_{13}$ FSI and LiTFSI, ${ }^{19,20}$ which prevent the formation of the crystalline $\mathrm{P}(\mathrm{EO})_{6} \mathrm{LiX}$ phase. ${ }^{21}$ We can suppose that the $\mathrm{Li}^{+} \mathrm{FSI}^{-}$interactions play a key role also in the PEO-LiTFSI-PYR ${ }_{13}$ FSI-EC quaternary system, reducing the role of the $\mathrm{PEO}$ chains in the coordination of the $\mathrm{Li}^{+}$cations and, therefore, enhancing the lithium ion mobility (i.e., preventing also formation of the $\mathrm{P}(\mathrm{EO})_{6} \mathrm{LiX}$ complex). In addition, ionic liquid percolation (due to liquid phase separation) gives additional contribute to the transport properties. A remarkable increase (with respect to the IL-free sample) in ion conduction (up to three orders of magnitude at $20^{\circ} \mathrm{C}$ ) is seen up to a $\mathrm{PYR}_{13}: \mathrm{Li}$ mole ratio $=2$. Further addition of IL does not lead to relevant raise in conductivity (as also reveled in Figure 4C) in the whole temperature range investigated, with the exception of a modest increase around $40^{\circ} \mathrm{C}$ as also reported in Figure 6. This behavior (evidenced for $\mathrm{PYR}_{13}: \mathrm{Li}>2$ and, once more, in agreement with the DSC results) is clearly correlated to the ionic liquid fraction within the PEO electrolyte.

The Arrhenius conductivity diagram of the PMMA-based quaternary $\mathrm{Li}^{+}$-conducting membranes (Figure 7B) displays continuous slope change, ascribable to VTF behavior typical of amorphous polymer electrolytes. ${ }^{13,14}$ As well as for the analogous PEO system, the ionic liquid plays a key role in improving the ion transport properties. For instance, conduction raises up to four and two orders of magnitude are seen at 20 and $70^{\circ} \mathrm{C}$ (Table I), respectively, in moving from a $\mathrm{PYR}_{13}$ :Li mole ratio $=3$ to 5 . However, the PMMA electrolytes exhibit conductivity values one order of magnitude lower with respect to PEO samples (Figure 7A) having analogous composition (Table I). Such differences in ion conduction may be attributed to the absence of 3-D, conductive, liquid networks (hypothesized in PEO electrolytes), probably due to the stronger interactions of $\mathrm{PYR}_{13} \mathrm{FSI}$ with the PMMA host (resulting in lower IL segregation).

\section{Conclusions}

Quaternary, PEO- and PMMA based, $\mathrm{Li}^{+}$-conducting membranes, to be addressed as electrolyte separators for lithium polymer battery systems, containing large amount (up to $60 \mathrm{wt} \%$ ) of the $N$-methyl- $N$ propylpyrrolidinium bis(fluorosulfonyl)imide $\left(\mathrm{PYR}_{13} \mathrm{FSI}\right.$ ) ionic liquid were properly designed and developed with the aiming to allow fast ion mobility even below room temperature. The electrolyte samples were investigated in terms of thermal and ion transport properties as a function of the temperature and $\mathrm{PYR}_{13}: \mathrm{Li}$ mole ratio.

Ionic conductivities equal to $1.5 \times 10^{-4}$ and $1.6 \times 10^{-3} \mathrm{~S} \mathrm{~cm}^{-1}$ were observed, in $\mathrm{PEO}$ electrolytes, at $-20^{\circ} \mathrm{C}$ and $20^{\circ} \mathrm{C}$, respectively, in combination with good mechanical properties. These represent ones of the highest, if not the highest, ion conduction values never reported for ionic liquid-based PEO electrolytes. In addition, no degradation of the mechanical and transport properties was observed even upon prolonged storage time periods (about 1.5 years). Less fast transport properties were seen for the PMMA electrolyte system, which exhibited ion conduction equal to $5.4 \times 10^{-6}$ and $5.4 \times 10^{-5} \mathrm{~S} \mathrm{~cm}^{-1}$ at $-20^{\circ} \mathrm{C}$ and $20^{\circ} \mathrm{C}$, respectively.

The results coming from thermal and impedance investigations suggest ionic liquid percolation through the polymer bulk for PEO electrolytes (exhibiting liquid leakage upon few days of storage) whereas progressive ionic liquid diffusion from the core to external regions was hypothesized for the PMMA membranes. Work is actually in progress in our laboratory for deeply investigating this issue. Nodaway, these quaternary electrolyte membranes result appealing as separators for lithium polymer batteries.

\section{Acknowledgment}

The authors wish to acknowledge the EU for funding within the MARS-EV Project (FP7 - Contract n ${ }^{\circ}$ 609201).

\section{References}

1. J. M. Tarascon and M. Armand, Nature (London), 414, 359 (2001).

2. R. Frech, S. Chintapalli, P. G. Bruce, and C. A. Vincent, Macromolecules, 32, 808 (1999).

3. P. V. Wright, British Polymer Journal, 7, 319 (1975).

4. M. Armand, J. M. Chabagno, and M. Duclot, Polyethers as solid electrolytes, in P. Vashitshta, J. N. Mundy, and G. K. Shenoy, Fast ion transport in solids. Electrodes and Electrolytes, North Holland Publishers, Amsterdam (1979).

5. F. M. Gray, Polymer Electrolytes, Royal Society of Chemistry Monographs, Cambridge (1997).

6. S. Passerini, M. Montanino, and G. B. Appetecchi, Lithium Polymer Batteries based on Ionic Liquids, in Polymers for Energy Storage and Conversion, Vikas Mittal editor, John Wiley and Scriverner Publishing, USA (2013).

7. O. Miguel, Materials for Ageing Resistant Li-ion High Energy Storage for the Electric Vehicle, European Electric Vehicles Congress (EEVC-2014), Brussels, December 2 (2014). 
8. G. B. Appetecchi, M. Montanino, and S. Passerini, Ionic Liquid-based Electrolytes for High-Energy Lithium Batteries in Ionic Liquids Science and Applications, ACS Symposium Series1117, A. E. Visser, N. J. Bridges, and R. D. Rogers editors, Oxford University Press, Inc., American Chemical Society, Washington, DC, USA (2013).

9. M. Montanino, S. Passerini, and G. B. Appetecchi, Electrolytes for rechargeable lithium batteries, in Rechargeable lithium batteries: from fundamentals to applications, Alejandro A. Franco editor, Woodhead Publishing, UK (2015).

10. M. Montanino, M. Moreno, M. Carewska, G. Maresca, E. Simonetti, R. Lo Presti, F. Alessandrini, and G. B. Appetecchi, J. Power Sources, 269, 608 (2014).

11. M. Montanino, F. Alessandrini, S. Passerini, and G. B. Appetecchi, Electrochim. Acta, 96, 124 (2013).

12. G. B. Appetecchi, W. Henderson, P. Villano, M. Berrettoni, and S. Passerini, $J$ Electrochem. Soc., 148, 1171 (2001).
13. G. B. Appetecchi, G. Dautzenberg, and B. Scrosati, J. Electrochem. Soc., 143, 6 (1996).

14. Y. Aihara, G. B. Appetecchi, and B. Scrosati, J. Electrochem. Soc., 149, A849 (2002).

15. web-site: www.xpolymers.it/temperatura di fusione.html

16. J. R. MacDonald in Impedance Spectroscopy, John Wiley and Sons, Editors, New York (1987).

17. S. Kirkpatrick, Rev. Mod. Phys., 45, 574 (1973).

18. G. B. Appetecchi, M. Montanino, M. Carewska, F. Alessandrini, and S. Passerini, ECS Transactions, 25(36), 49 (2010).

19. M. Castriota, T. Caruso, R. G. Agostino, E. Cazzanelli, W. A. Henderson, and S. Passerini, J. Phys. Chem. A, 109, 92 (2005).

20. I. Nicotera, C. Oliviero, W. A. Henderson, G. B. Appetecchi, and S. Passerini, J. Phys. Chem. B, 109, 22814 (2005).

21. J. -H. Shin, W. A. Henderson, and S. Passerini, J. Electrochem. Soc., 152, A978 (2005). 